\title{
Petroselinum Crispum is Effective in Reducing Stress-Induced Gastric Oxidative Damage
}

\author{
Ayşin Akınc11, Mukaddes Eşrefoğlu22, Elif Taşlıdere2, Burhan Ateş3 \\ ${ }^{1}$ Doğu Fertil IVF Center, Malatya, Turkey \\ ${ }^{2}$ Department of Histology and Embryology, Bezmialem Vakıf University Faculty of Medicine, İstanbul, Turkey \\ ${ }^{3}$ Department of Chemistry, İnönü University Faculty of Science and Art, Malatya, Turkey
}

Background: Oxidative stress has been shown to play a principal role in the pathogenesis of stress-induced gastric injury. Parsley (Petroselinum crispum) contains many antioxidants such as flavanoids, carotenoids and ascorbic acid.

Aims: In this study, the histopathological and biochemical results of nutrition with a parsley-rich diet in terms of eliminating stress-induced oxidative gastric injury were evaluated.

Study Design: Animal experimentation.

Methods: Forty male Wistar albino rats were divided into five groups: control, stress, stress + standard diet, stress + parsley-added diet and stress + lansoprazole (LPZ) groups. Subjects were exposed to 72 hours of fasting and later immobilized and exposed to the cold at +4 degrees for 8 hours to create a severe stress condition. Samples from the animals' stomachs were arranged for microscopic and biochemical examinations.

Results: Gastric mucosal injury was obvious in rats exposed to stress. The histopathologic damage score of the stress group $(7.00 \pm 0.57)$ was higher than that of the control group $(1.50 \pm 0.22)(\mathrm{p}<0.05)$. Significant differences in histopathologic damage score were found between the stress and stress + parsley-added diet groups $(\mathrm{p}<0.05)$, the stress and stress + standard diet groups $(p<0.05)$, and the stress and stress + LPZ groups $(p<0.05)$. The mean tissue malondialdehyde levels of the stress + parsley-added group and the stress + LPZ group were lower than that of the stress group $(p<0.05)$. Parsley supported the cellular antioxidant system by increasing the mean tissue glutathione level $(53.31 \pm 9.50)$ and superoxide dismutase $(15.18 \pm 1.05)$ and catalase (16.68 \pm 2.29$)$ activities.

Conclusion: Oral administration of parsley is effective in reducing stress-induced gastric injury by supporting the cellular antioxidant defence system.

Keywords: Lansoprazole, gastric oxidative damages, parsley
Stress, one of the biggest problem of our era, is an important factor that underlies many diseases. Reactive oxygen species (ROS) have been identified as playing a prominent role in the pathogenesis of ulcerative damage induced by stress (1). Stress has been shown to accelerate the formation of ROS (2-4). Free oxygen radicals are highly reactive and attack all of the cellular components such as cell lipids, proteins, carbohydrates and DNA $(5,6)$. Antioxidant nutrients are important for the body for protection against ROS. In fact, the cells of the body are capable of producing enzymatic antioxidants including superoxide

Address for Correspondence: Dr. Elif Taşlıdere, Department of Histology and Embryology, Bezmialem Vakıf University Faculty of Medicine, İstanbul, Turkey

Phone: +905056680494 e-mail: eliftaslidere@hotmail.com

Received: 07 October $2015 \quad$ Accepted: 07 August 2016 • DOI: 10.4274/balkanmedj.2015.1411

Available at www.balkanmedicaljournal.org

Cite this article as:

Akıncı A, Eşrefoğlu M, Taşlıdere E, Ateş B. Petroselinum Crispum is Effective in Reducing Stress-Induced Gastric Oxidative Damage. Balkan Med J 2017;34:53-9

${ }^{\circ}$ Copyright 2017 by Trakya University Faculty of Medicine / The Balkan Medical Journal published by Galenos Publishing House. 
dismutase (SOD), catalase (CAT) and glutathione peroxidase (GSH-Px) as well as non-enzymatic antioxidants including GSH. SOD scavenges superoxide $\left(\mathrm{O}_{2}^{\bullet-}\right)$ whereas CAT and GSH-Px scavenge hydrogen peroxide $\left(\mathrm{H}_{2} \mathrm{O}_{2}\right)$ (7-9).

$\mathrm{H}_{2}$ receptor blockers and proton pump inhibitors (PPIs) are drugs introduced in clinical use in the treatment of gastric ulcers. PPIs, e.g. omeprazole, lansoprazole (LPZ), pantoprazole and esomeprazole, are the most effective inhibitors of gastric acid secretion. LPZ is metabolized to sulfonamide derivatives in parietal cells. The resultant metabolites inactivate the $\mathrm{H}+$ / $\mathrm{K}+$ ATPase enzyme system, and block the formation of acid by preventing the migration of the $\mathrm{H}+$ ions into the lumen $(10,11)$. LPZ can also scavenge free oxygen radicals and thereby maintain the gastric mucosal epithelium and vascular endothelium (12). In cases of peptic ulcers, a $30 \mathrm{mg} /$ day dose for 8 weeks is recommended for healing (13).

Numerous studies have been performed in order to evaluate the efficacy of many nutrients of antioxidant properties against stress-induced tissue damage. Parsley (Petroselinum crispum) is an aromatic herb that has been used to give flavour and odour to dishes and salads for centuries (14-17). In addition, Petroselinum crispum is now planted throughout the world due to its usage in the food industry, perfume manufacturing, soaps and creams $(18,19)$. Parsley is rich in several antioxidants including volatile oils (apiol, limonene and eugenol), flavonoids (luteolin, apigenin glycosides and quercetin), carotenoids, ascorbic acid, tocopherol, tannins, sterols, vitamins $\mathrm{A}, \mathrm{C}$ and $\mathrm{K}$, potassium, calcium and magnesium (14-17,20,21). Due to its flavonoid, carotenoid and ascorbic acid content, it is a potent free radical scavenger (22). Flavonoids have been shown to be effective in the treatment of gastric ulcers $(23,24)$. Parsley was reported to scavenge the free radicals $\mathrm{OH}$ - and 2,2-diphenyl-1-picrylhydrazil, and thus to reduce lipid peroxidation (25).

A variety of experimental animal models have been developed to generate stress ulcers. The most commonly used methods are immobilization, cold exposure and swimming. In our study, we tried to generate a severe stress condition by applying starvation, immobilization and cold. We aimed to investigate stress-induced gastric mucosal alterations and the efficacy of parsley in comparison to LPZ via histological and biochemical methods.

\section{MATERIALS AND METHODS}

\section{Experimental protocol}

In this study, 40 adult male Wistar albino rats were used. Animals were fed with standard rat chow and tap water ad libitum and were maintained in a $12 \mathrm{~h} \mathrm{light} / 12 \mathrm{~h}$ dark cycle at $21^{\circ}$.
Subsequently the rats were randomly divided into five groups (each containing eight animals). The first group represented intact control. The rats from the second, third, fourth and fifth groups were exposed to starvation for 72 hours. At the end of the starvation period they were immobilized and kept at $4{ }^{\circ} \mathrm{C}$ for 8 hours. The rats from the stress group (2nd group) were decapitated after the stress exposure. Animals from the stress + standard diet group (3rd group) were fed with standard rat chow for 7 days. Animals from the stress + parsley (Petrocelinum crispum; herbarium number: INU1199-2013 from XXXX University, Faculty of Art and Science, Department of Botany)added diet group (4th group) were fed with a diet in which a $28 \mathrm{~g} / \mathrm{kg}$ body weight/day dose of parsley (40\%) was added to the standard diet for 7 days. Finally, rats from the stress + LPZ group (5th group) were administered a $0.5 \mathrm{mg} / \mathrm{kg} /$ day dose of LPZ (LPZ $30 \mathrm{mg}$, Nobel, Düzce, Turkey) dissolved in $4 \mathrm{~mL}$ of normal saline via gavages for 7 days.

The rats were sacrificed by cervical dislocation at the end of the experiment. The stomachs were removed and opened by cutting along the lesser curvature. A half portion of the body of the stomach was processed for histological evaluation, and the other half for biochemical analysis.

The experiments were performed in accordance with the Guidelines for Animal Research from the National Institutes of Health and was approved by the Committee on Animal Research at İnönü University, Malatya, Turkey (2007/67).

\section{Histopathological examination}

Samples prepared with a routine histological technique and sections were examined and scored using a Leica DFC280 light microscope and a Leica Q Win 1000 image analysis system (Leica Microsystems Imaging Solutions Ltd., Cambridge, UK). Assessment of tissue alterations in 20 different fields for each section was con-ducted by an experienced histologist who was unaware of the treatment. Gastric injury was scored by grading mucosal injury, congestion, haemorrhage and cell infiltration damage with a maximum score of 15 . Scoring was performed for each parameter as follows: $0=$ no change, $1=$ mild, $2=$ moderate, $3=$ severe.

\section{Biochemical examination}

The tissues were weighed for measurement of enzyme activities or levels, a PBS buffer with a ratio of $1 / 5 \mathrm{w} / \mathrm{v}(\mathrm{pH}$ : 7.4) was added and all the tissues were homogenized with packed cell volume, Kinematica, Status homogenizer (IKA-WERKE Ultra-Turrax, Germany) under ice isolation until they were all degraded. The resulting homogenates were sonified three times at 30-second intervals for 30 seconds with a VWR Scientific Branson sonificator (VWR Int. Ltd. Merch House Pool, UK). After the homogenization and sonification procedures, they 
were centrifuged at $12000 \mathrm{~g}$ for $15 \mathrm{~min}$ in an Ole Dich 157. MP micro centrifuge instrument (Ole Dich 157.MP micro centrifuge, Hvidovre, Denmark) at $4{ }^{\circ} \mathrm{C}$. Thus, the supernatant in which enzyme and protein assays would be conducted was obtained. CAT, SOD and GSH-Px activities and GSH and malondialdehyde (MDA) levels were determined using the methods in the references (26-30).

\section{Statistical analysis}

Statistical analyses were performed using the Kruskal-Wallis analysis of variance and Mann-Whitney $U$ test on SPSS statistical software (SPSS for Windows version 13, SPSS Inc., Chicago, IL). All results were expressed as mean \pm standard deviation (SD) (mean $\pm \mathrm{SD}$ ) and median (min-max). $\mathrm{P}<0.05$ was considered statistically significant.

\section{RESULTS}

\section{Macroscopic results}

Hyperaemia and petechia were observed at the inner surface of the stomachs of rats exposed to stress (Figure 1).

\section{Microscopic results}

Sections from the control group presented normal histology. However, several alterations indicating mucosal injury were detected in the sections of the rats exposed to stress. Degeneration and desquamation of the surface epithelium were observed (Figure 2). Congestion, haemorrhage and cell infiltration were detected in connective tissue. Periodic acid-Schiff (PAS)-Alcian blue staining on the surface and within the glandular lumen was pale and sometimes negative. In the sections obtained from the animals on a standard diet, mild mucosal damage was detected. PAS-Alcian blue staining on the surface and within the glandular lumen was also pale and sometimes negative (Figure 3). Sections from animals on the parsley-added diet were generally normal in histological appearance (Figure 4A), and the mucus
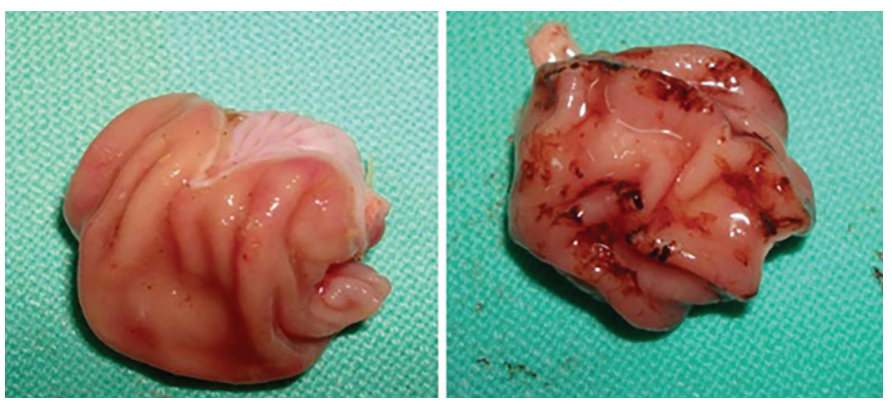

FIG. 1. Macroscopic appearance of the inner gastric surface of a rat from the control group on the left and from the stress group on the right. Hyperaemia and haemorrhagic spots induced by stress are very obvious. layer on the surface was well preserved and very thick (Figure 4B). Sections of LPZ-treated rats very rarely showed epithelial desquamation (Figure 5). PAS-Alcian blue staining of the stress + LPZ group was positive in the cytoplasm of glandular cells, surface epithelial cells and on the surface. The mucus layer covering the epithelial surface was generally very thick.

The histopathologic damage score (HDS) was significantly higher in the stress group than the control group $(\mathrm{p}<0.05)$.

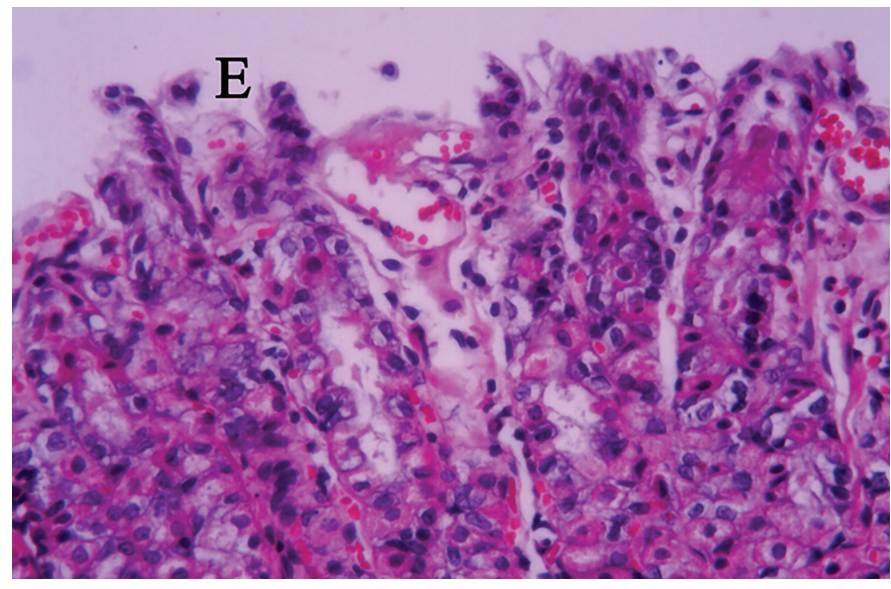

FIG. 2. Stress group. Degeneration within the epithelium (E) and lamina propria was observed. HE; x20.

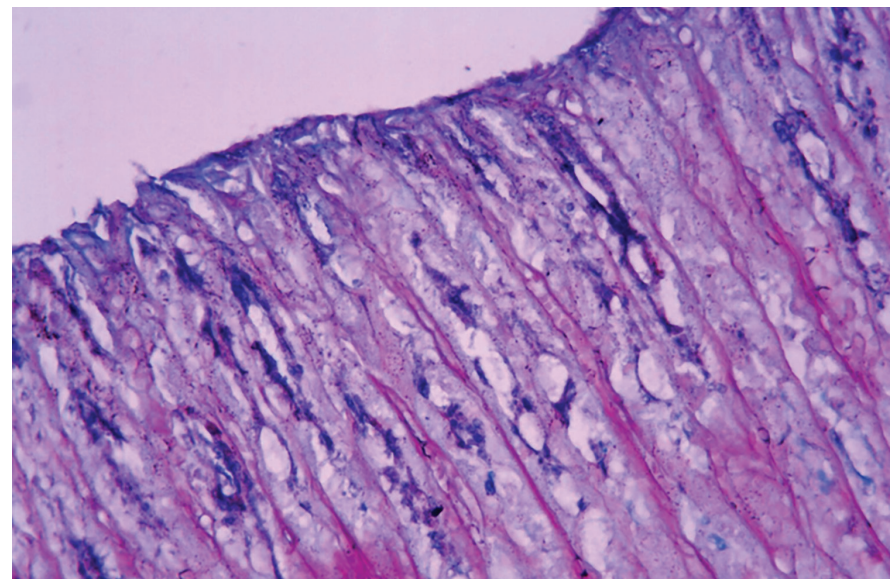

FIG. 3. Stress + standard diet group. A weak staining is seen. PAS-AL; $\mathrm{x} 40$.

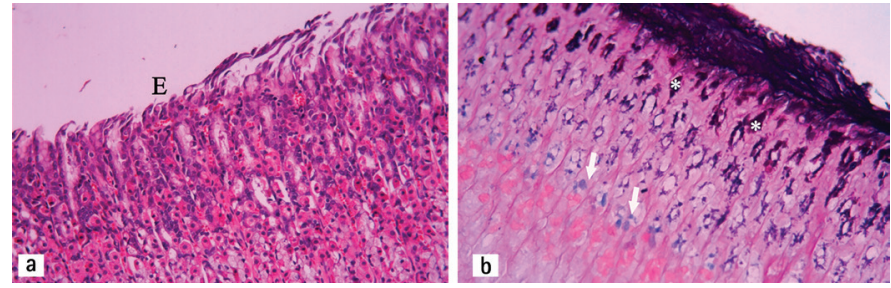

FIG. 4. A. Stress + parsley-added diet group. Epithelial flattening (E) and degeneration are seen. HE; x20. B. Stress + parsley-added diet group. Positively stained thick mucus is observed on the surface. Violet colour in apical part of the glands $\left(^{*}\right)$ and blue colour (arrows) in the middle parts of the glands (arrows) staining was observed. PAS-Al; $x 20$. 
The HDSs were $1.50 \pm 0.22$ in control group, $7.00 \pm 0.57$ in stress group, $4.00 \pm 0.17$ in animals subjected to a normal diet, $3.83 \pm 0.30$ in those subjected to a parsley-added diet and $2.33 \pm 0.33$ in animals treated with LPZ. A statistically significant difference was found between the stress and stress + parsleyadded diet groups $(\mathrm{p}<0.05)$, and the stress and stress + standard diet groups $(p<0.05)$. Additionally, a statistically significant difference was found between the stress group and the stress + LPZ group $(\mathrm{p}<0.05)$. Among all groups except the control, the lowest HDS belonged to the LPZ-treated group. LPZ treatment was more effective than parsley-added diet administration $(\mathrm{p}<0.05)$.

\section{Biochemical results}

The mean tissue MDA levels were also different between the groups. The MDA level of the stress group was significantly higher than that of the control group $(\mathrm{p}<0.05)$. The MDA levels

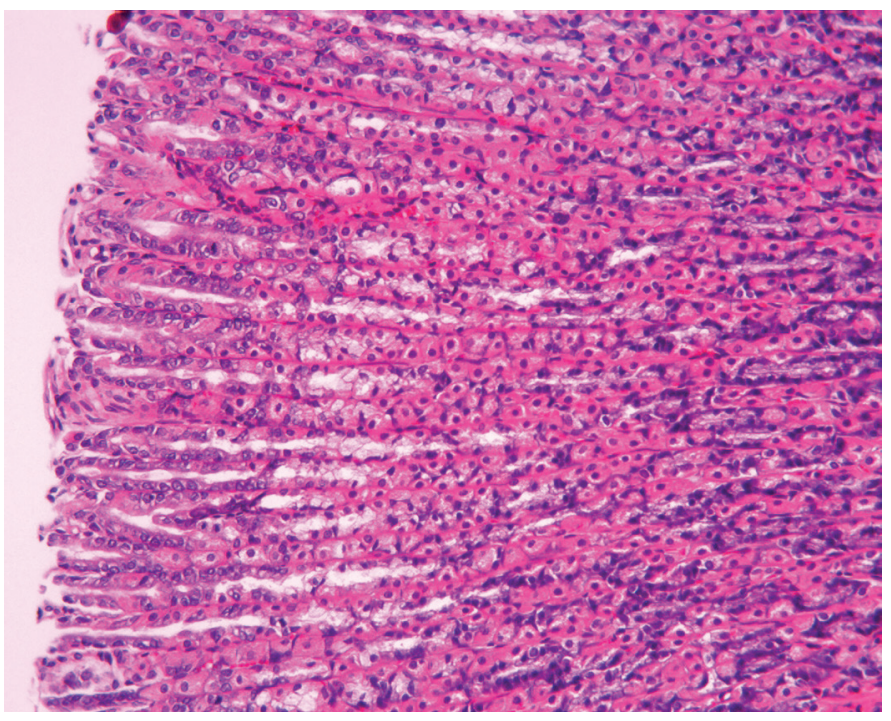

FIG. 5. Stress + LPZ group. A normal histological appearance is seen. $\mathrm{HE} ; \mathrm{x} 20$. were $0.73 \pm 0.05$ in the control group, $0.88 \pm 0.02$ in the stress group, $0.78 \pm 0.05$ in the stress + standard diet group, $0.72 \pm 0.03$ in the stress + parsley-added diet group and $0.71 \pm 0.04$ in the stress + LPZ group. The MDA levels of the stress + parsleyadded diet group and stress + LPZ group were lower than that of the stress group $(p<0.05)$. The mean tissue MDA levels together with MDA are summarized in Table 1.

The GSH level and SOD and GSH-Px activities of the stress group were lower than those of the control group $(\mathrm{p}<0.05)$. In contrast, the CAT activity of the stress group was higher than that of the control group $(\mathrm{p}<0.05)$. The CAT activity of the stress + parsley-added diet group was higher than that of the control group $(p<0.05)$. The lowest SOD activity was found in the stress group whereas the highest was found in the stress + parsley-added diet group. A significant difference was found between the stress group and the stress + parsley-added diet group $(p<0.05)$. The GSH-Px values of the stress + standard diet group were higher than that of the stress + parsley-added diet group $(\mathrm{p}<0.05)$. The GSH levels of all groups were higher than that of the stress group. The GSH levels of the stress + parsley-added diet group were significantly higher than that of the stress group $(p<0.05)$. The closest value to that of the control group was found in the stress + parsley-added diet group. The GSH levels and GSH-Px activities, and CAT and SOD activities of all groups, are shown in Table 1.

\section{DISCUSSION}

Clinical and experimental studies have revealed that increased amounts of free radicals induce lipid peroxidation in various stress models (4,31-33). In this study, we also found a stressinduced increase in mean tissue MDA levels. The mean tissue MDA level and HDS of the stress group were significantly higher than in the control group $(\mathrm{p}<0.05)$.

In the present study, the tissue GSH level $(\mathrm{p}<0.05)$ together with GSH-Px $(p<0.05)$ and SOD activities $(p<0.05)$ were significantly

TABLE 1. The levels of biochemical parameters of all groups

\begin{tabular}{|c|c|c|c|c|c|}
\hline Parameters & Control & Stress & Stress + standard diet & Stress+parsley & Stress+LPZ \\
\hline \multirow[t]{2}{*}{ MDA } & $0.73 \pm 0.12$ & $0.88 \pm 0.04$ & $0.79 \pm 0.11$ & $0.72 \pm 0.18 \mathrm{a}$ & $0.71 \pm 0.08^{\mathrm{a}}$ \\
\hline & $0.76(0.57-0.86)$ & $0.88(0.80-0.93)$ & $0.80(0.64-0.91)$ & $0.72(0.58-0.84)$ & $0.72(0.58-0.83)$ \\
\hline \multirow[t]{2}{*}{ CAT } & $5.92 \pm 1.42$ & $14.69 \pm 2.42^{\mathrm{b}}$ & $7.71 \pm 1.60^{\mathrm{a}}$ & $16.68 \pm 2.29 \mathrm{~b}, \mathrm{c}$ & $8.99 \pm 2.62^{\mathrm{a}, \mathrm{d}}$ \\
\hline & $5.56(4.52-7.72)$ & $13.6(12.6-18.7)$ & $7.01(6.09-10.3)$ & $17(12.7-19.5)$ & $8.45(6.5-13)$ \\
\hline \multirow[t]{2}{*}{ SOD } & $16.68 \pm 1.41$ & $12.77 \pm 1.50$ & $14.29 \pm 2.48$ & $15.18 \pm 1.05^{\mathrm{e}}$ & $14.79 \pm 1.92$ \\
\hline & $16.3(15.5-19.3)$ & $13.26(10.4-14.3)$ & $14.28(10.9-17.2)$ & $15.4(13.5-16.4)$ & $15.3(11.5-16.6)$ \\
\hline \multirow[t]{2}{*}{ GSH } & $61.44 \pm 12.3$ & $38.20 \pm 9.83$ & $48.69 \pm 8.52$ & $53.31 \pm 9.50^{\mathrm{e}}$ & $47.08 \pm 5.65$ \\
\hline & $59.1(47.5-81.2)$ & $40.76(20.1-47.5)$ & $48.8(38.6-59.3)$ & & $46.6(39.7-56.4)$ \\
\hline \multirow[t]{2}{*}{ GSH-Px } & $49.50 \pm 11.4$ & $32.92 \pm 7.21$ & $38.48 \pm 7.27$ & $28.43 \pm 6.25^{\mathrm{a}, \mathrm{f}}$ & $43.12 \pm 8.05$ \\
\hline & $48.2(36.1-65.2)$ & $31.25(25.7-43.2)$ & $37.8(28.5-47.7)$ & $28.4(22-38.9)$ & $40.1(34.4-54.3)$ \\
\hline
\end{tabular}

Data were presented as mean \pm standard deviation and median (min-max), MDA: malondialdehyde, SOD: superoxide dismutase, CAT: catalase, GSH-Px: glutathione peroxidase, GSH: glutathione, a: Significant decrease $(\mathrm{p}=0.03)$, vs. stress group, ${ }^{\mathrm{b}}$ : Significant increase $(\mathrm{p}=0.001)$, vs. control group, ${ }^{\mathrm{c}}$ : Significant increase $(\mathrm{p}=0.001)$, vs. stress $+\mathrm{standard}$ diet group, ${ }^{\mathrm{d}}$ : Significant decrease $(\mathrm{p}=0.03)$, vs. stress + parsley group, ${ }^{\text {: }}$ : Significant increase $(\mathrm{p}=0.03)$, vs. stress group, : Significant decrease $(\mathrm{p}=0.003)$, vs. stress + standard diet group 
decreased whereas CAT activity $(\mathrm{p}<0.05)$ was significantly increased in the stress group. Similarly to our results, decreases in tissue SOD activity (34-36), GSH-Px activity $(37,38)$ and GSH level (30,39), and an increase in CAT activity (38), have been found. However, in some studies, no changes in SOD activity (38), increase in SOD activity (40) or decrease in CAT activity have been reported $(39,40)$. Although the term 'oxidative stress' describes the insufficiency of the cellular antioxidant system against oxidant agents, the levels or the activities of the antioxidant enzymes have not been reported to be decreased in stress situations. The cells try to protect themselves initially via increased amounts of antioxidant enzyme production when they are exposed to any oxidant agent. This stage is probably a compensatory period. As a result of the damage of the organelles related to the production of the antioxidant enzymes, the amounts of the antioxidant enzymes decrease. In our study, SOD and GSH-Px activities and GSH levels were decreased but CAT activity was increased during the same stress period.

Conflicting results of studies emphasize the importance of detecting multiple antioxidant enzyme levels in order to evaluate the cellular antioxidant defence system. The response of each enzyme to oxidative agents may be different. Various factors, including the type and duration of the stress, the type of tissue and the species of the experimental animals, could be reasons for the conflicting results.

HSDs were $7.0 \pm 0.57$ in the stress group $(\mathrm{p}<0.05)$ and $4.00 \pm 0.17$ in the stress + standard diet group $(\mathrm{p}<0.05)$. We suggest that this recovery, even if no therapeutic agent had been applied, shows the self-repair capacity of the tissue that occurred within 7 days following the application of stress. Indeed, the tissue MDA level was decreased in this group in comparison to the stress group. Increases in SOD and GSH-Px activities and GSH levels are in fact indicators of time-dependent recovery of cellular antioxidant defence.

Parsley is a powerful antioxidant and free radical scavenger, especially due to its flavonoid content $(14,15,20)$. Flavonoids show antioxidant, anti-inflammatory, anti-secretory, antiproliferative and anti-ulcer effects in the gastrointestinal tract $(41,42)$. To the best of our knowledge, the present study is the first to investigate the effect of fresh parsley on the gastric damage induced by stress. In fact, this study was inspired by, and based on, the experience of one of our authors whose gastric burning and pain induced by stress were relieved shortly after ingesting fresh parsley. In line with this experience, HDS and MDA levels were decreased in the stress + parsley-added diet group. The differences between the stress + standard diet and stress + parsley-added groups in particular emphasize the benefit of fresh parsley added to a daily diet. In different ulcer models, many plants like parsley containing tannins, sterols and flavonoids were found to protect gastric mucus and reduce MDA levels (17,43-46). Plants that contain flavonoids have been reported to increase CAT, GSH and SOD activities in stress-induced ulcers (37-46). In the present study, the mean CAT and SOD activities and GSH levels of animals from the stress + parsley-added diet group were higher than those of the stress and stress + standard diet groups. The increase in CAT activity in the stress + parsley-added diet group in relation to the stress + standard diet group was particularly noteworthy. The biochemical results show that parsley strongly supports the antioxidant enzyme system. Nielsen et al. (47) have reported increases in erythrocyte GSH reductase and SOD activities after nutrition with a parsley-rich diet for 2 weeks in a voluntary group consisting of 14 healthy people.

The mucus layer covering the epithelial surface of the gastrointestinal tract is an important protective layer (48). In our study, a weak staining was observed on the surface and glandular epithelium of the animals exposed to stress. In particular, the thickness of the superficial mucus is significantly reduced and absent in some areas. In contrast, in the stress + parsley-added diet group, PAS staining was very positive within the surface and glandular epithelium, and on the surface. This layer was found to be quite thick in some areas. Al-Howiriny et al. (17) found that mucus secretion was improved with the application of parsley. We suggest that the supportive effect of parsley on the gastric mucus barrier plays an important role in its beneficial effect on improving oxidative damage.

$\mathrm{H}_{2}$ receptor blockers and PPIs are commonly used drugs in the treatment of stress ulcers $(10,12)$. LPZ is a PPI that inhibits the $\mathrm{H}+/ \mathrm{K}+$ ATPase enzyme in parietal cells. In experimental ulcer models, the therapeutic capacity of LPZ depends mainly on its suppressing effect on acid secretion and the amount of gastric pepsin $(49,50)$ and on the effect of scavenging $\mathrm{OH}$ - radicals (51,52). Nakamura et al. (53) have demonstrated that LPZ increases microvascular and connective tissue regeneration in particular in the treatment of ulcers generated by ethanol.

In the present study, we also found a significantly reduced HDS in the stress + LPZ group compared to the stress group $(\mathrm{p}<0.05)$. Maiti et al. (54) and Blandizzi et al. (55) found LPZ effective in protecting gastric mucosa. The therapeutic effect of LPZ on gastric mucosal damage is found to be related to its mucusincreasing effect rather than its aciddecreasing effect (56-58). Nakamura et al. (53) found that the relationship between the structure consisting of mucus, cell debris and proteins, known as the "mucoid cap", and myofibroblasts is important for gastric healing. Researchers concluded that acid suppression is important in the early stages of recovery with LPZ, but that the gastric mucosal defence mechanisms should be maintained for long-term recovery. In this study, we observed that LPZ 
administration increased the amount of mucus. This layer was found to be quite thick in some areas.

In the present study, LPZ reduced HDS and MDA levels, but increased SOD and GSH-Px activities and the GSH level compared to the stress group. CAT activity was higher than that of the control group. In ulcer studies, increased MDA and SOD values, and decreased CAT, GSH and GSH-Px values or decreased MDA and SOD values, and increased CAT, GSH and GSH-Px values have been reported $(34-40,59,60)$. LPZ was shown to increase sulfhydryl compounds such as GSH in particular, and thereby prevent gastric damage $(55,61)$. LPZ, indeed, is known to support the antioxidant system $(52,59,60)$. In conclusion, the addition of fresh parsley to the diet of experimental animals is effective in decreasing stress-induced gastric mucosal damage by supporting the cellular antioxidant enzyme system. It is exciting to realize that fresh parsley is more effective than LPZ in supporting tissue GSH levels and CAT activities. We suggest that a fresh parsley-rich diet together with classical drug treatment may accelerate the healing process.

Acknowledgement: This study was supported by the fund of İnönü University Scientific Project Research Unit, Malatya, Turkey (2008/16).

Conflict of Interest: No conflict of interest was declared by the authors.

\section{REFERENCES}

1. Bandyopadhyay D, Chattopadhyay A. Reactive oxygen species-induced gastric ulceration: protection by melatonin. Curr Med Chem 2006;13:1187-202.

2. Jia YT, Ma B, Wei W, Xu Y, Wang Y, Tang HT, et al. Sustained activation of nuclear factor-kappaB by reactive oxygen species is involved in the pathogenesis of stress-induced gastric damage in rats. Crit Care Med 2007;35:1582-91.

3. Jia YT, Wei W, Ma B, Xu Y, Liu WJ, Wang Y, et al. Activation of p38 MAPK by reactive oxygen species is essential in a rat model of stressinduced gastric mucosal injury. J Immunol 2007;179:7808-19.

4. Sahin E, Gümüşlü S. Stress-dependent induction of protein oxidation, lipid peroxidation and anti-oxidants in peripheral tissues of rats: comparison of three stress models (immobilization, cold and immobilization-cold). Clin Exp Pharmacol Physiol 2007;34:425-31.

5. Birben E, Sahiner UM, Sackesen C, Erzurum S, Kalayci O. Oxidative stress and antioxidant defense. World Allergy Organ J 2012;5:9-19.

6. Valko M, Rhodes CJ, Moncol J, Izakovic M, Mazur M. Free radicals, metals and antioxidants in oxidative stress-induced cancer. Chem Biol Interact 2006;160:1-40.

7. Gebicki JM, Nauser T, Domazou A, Steinmann D, Bounds PL, Koppenol WH. Reduction of protein radicals by GSH and ascorbate: potential biological significance. Amino Acids 2010;39:1131-7.

8. Seifried HE, Anderson DE, Fisher EI, Milner JA. A review of the interaction among dietary antioxidants and reactive oxygen species. J Nutr Biochem 2007;18:567-79.

9. Valko M, Leibfritz D, Moncol J, Cronin MT, Mazur M, Telser J. Free radicals and antioxidants in normal physiological functions and human diseases. Int J Biochem Cell Biol 2007;39:44-84.
10. Gremse DA. Lansoprazole: pharmocokinetics, pharmocodynamics and clinical uses. Expert Opin Pharmacother 2001;2:1663-70.

11. Demir A, Aydin A. A new drug in the treatment of peptic ulcer disease: Lansoprazole. Turkiye Klinikleri J Gastroenterohepatol 1998;9:1-6.

12. Becker JC, Grosser N, Waltke C, Schulz S, Erdmann K, Domschke W, et al. Beyond gastric acid reduction: proton pump inhibitors induce heme oxygenase-1 in gastric and endothelial cells. Biochem Biophys Res Commun 2006;345:1014-21.

13. Colin-Jones DG. Safety of lansoprasole. Aliment Pharmacol Ther 1993;7(Suppl 1):56-60.

14. Altunbaş M, Turel I. The lethal dose levels of volatile oil extract of Petroselinum crispum (Parsley) seeds and the investigation of antiinflammatory effect on laboratory animals. YYU Vet Fak Derg 2009;20:215.

15. Fejes S, Blazovics A, Lemberkovics E, Petri G, Szoke E, Kery A. Free radical scavenging and membrane protective effects of methanol extracts from Anthriscus cerefolium L. (Hoffm.) and Petroselinum crispum (Mill.) nym. ex A.W. Hill. Phytother Res 2000;14:362-5.

16. Gadi D, Bnouham M, Aziz M, Ziyyat A, Legssyer A, Legrand C, et al. Parsley extract inhibits in vitro and ex vivo platelet aggregation and prolongs bleeding time in rats. J Ethnopharmacol 2009;125:170-4.

17. Al-Howiriny T, Al-Sohaibani M, El-Tahir K, Rafatullah S. Prevention of experimentally-induced gastric ulcers in rats by an ethanolic extract of 'Parsley' Petroselinum crispum. Am J Chin Med 2003;31:699-711.

18. Mahmood S, Hussain S, Malik F. Critique of medicinal conspicuousness of Parsley (Petroselinum crispum): a culinary herb of Mediterranean region. Pak J Pharm Sci 2014;27:193-202.

19. Haidari F, Keshavarz SA, Mohammad Shahi M, Mahboob SA, Rashidi MR. Effects of Parsley (Petroselinum crispum) and its Flavonol Constituents, Kaempferol and Quercetin, on Serum Uric Acid Levels, Biomarkers of Oxidative Stress and Liver Xanthine Oxidoreductase Aactivity in OxonateInduced Hyperuricemic Rats. Iran J Pharm Res 2011;10:811-9.

20. Tang EL, Rajarajeswaran J, Fung S, Kanthimathi MS. Petroselinum crispum has antioxidant properties, protects against DNA damage and inhibits proliferation and migration of cancer cells. J Sci Food Agric 2015;95:2763-71.

21. Dorman HJ, Lantto TA, Raasmaja A, Hiltunen R. Antioxidant, pro-oxidant and cytotoxic properties of parsley. Food Funct 2011;2:328-37.

22. Fejes S, Kéry A, Blázovics A, Lugasi A, Lemberkovics E, Petri G, et al. Investigation of the in vitro antioxidant effect of Petroselinum crispum (Mill.) Nym. ex A. W. Hill. Acta Pharm Hung 1998;68:150-6.

23. Mota KS, Dias GE, Pinto ME, Luiz-Ferreira A, Souza-Brito AR, HirumaLima CA, et al. Flavonoids with gastroprotective activity. Molecules 2009;14:979-1012.

24. Akinci A, Esrefoglu M, Cetin A, Ates B. Melatonin is more effective than ascorbic acid and $\beta$-carotene in improvement of gastric mucosal damage induced by intensive stress. Arch Med Sci 2015;11:1129-36.

25. Popovic M, Kaurinovic B, Jakovljevic V, Mimica-Dukic N, Bursac M. Effect of Parsley (Petroselinum crispum (Mill.) Nym. ex A.W. Hill, Apiaceae) extracts on some biochemical parameters of oxidative stress in mice treated with CCI (4). Phytother Res 2007;21:717-23.

26. Bradford MM. A rapid and sensitive method for the quantization of microgram quantities of protein utilizing the principle of protein-dye binding. Anal Biochem 1976;72:248-54.

27. Luck H. Methods of enzymatic analysis. New York: Verlag Chemie, Academic Press; 1963.

28. McCord JM, Fridovich, I. Superoxide dismutase. An enzymatic function for erythrocuprein (hemocuprein). J Biol Che 1969;244:6049-55.

29. Buege JA, Aust SD. Microsomal lipid peroxidation. Methods Enzymol 1978;52:302-10.

30. Lawrence RA, Burk RF. Glutathione peroxidase activity in seleniumdeficient rat liver. Biochem Biopys Res Commun 1976;71:952-8. 
31. Ates B, Dogru MI, Gul M, Erdogan A, Dogru AK, Yilmaz I, et al. Protective role of caffeic acid phenethyl ester in the liver of rats exposed to cold stress. Fundam Clin Pharmacol 2006;20:283-9.

32. Shian WM, Sasaki I, Kamiyama Y, Naito H, Matsuno S, Miyazawa T. The role of lipid peroxidation on gastric mucosal lesions induced by waterimmersion restrain stress in rats. Surg Today 2000;30:49-53.

33. Kwiecien S, Jasnos K, Magierowski M, Sliwowski Z, Pajdo R, Brzozowski $\mathrm{B}$, et al. Lipid peroxidation, reactive oxygen species and antioxidative factors in the pathogenesis of gastric mucosal lesions and mechanism of protection against oxidative stress - induced gastric injury. J Physiol Pharmacol 2014;65:613-22.

34. Kwiecien S, Brzozowski T, Konturek SJ. Effects of reactive oxygen species action on gastric mucosa in various models of mucosal injury. J Physiol Pharmacol 2002;53:39-50.

35. Kwiecien S, Brzozowski T, Konturek PCh, Konturek SJ. The role of reactive oxygen species in action of nitric oxide-donors on stress-induced gastric mucosal lesions. J Physiol Pharmacol 2002;53:761-73.

36. Kwiecień S, Brzozowski T, Konturek PC, Pawlik MW, Pawlik WW, Kwiecień N, et al. Gastroprotection by pentoxyfilline against stressinduced gastric damage. Role of lipid peroxidation, antioxidizing enyzmes and proinflammatory cytokines. J Physiol Pharmacol 2004;55:337-55.

37. Li T, Zhang XJ. Protective effect of somatostatin against stress injury of gastric mucosa may be related to the scavenge of free radicals. Sheng $\mathrm{Li}$ Xue Bao 1994;46:369-74.

38. Bohdanova OV, Kot LI, Lavrova KV, Ostapchenko LI. Functioning of tyrosine protein kinases and phosphatases in gastric mucosa cells under conditions of oxidative and nitrosative stress in gastric lesions. Ukr Biokhim Zh 2008;80:85-94.

39. Rao ChV, Verma AR, Vijayakumar M, Rastogi S. Gastroprotective effect of standardized extract of Ficus glomerata fruit on experimental gastric ulcers in rats. J Ethnopharmacol 2008;115:323-6.

40. Tandon R, Khanna HD, Dorababu M, Goel RK. Oxidative stres and antioxidants status in peptic ulcer and gastric carcinoma. Indian J Physiol Pharmacol 2004;48:115-8.

41. Leonarduzzi G, Testa G, Sottero B, Gamba P, Poli G. Design and development of nanovehicle-based delivery systems for preventive or therapeutic supplementation with flavonoids. Curr Med Chem 2010;17:74-95.

42. Zayachkivska OS, Konturek SJ, Drozdowicz D, Konturek PC, Brzozowski T, Ghegotsky MR. Gastroprotective effects of flavonoids in plant extracts. J Physiol Pharmacol 2005;56(Suppl 1):219-31.

43. Zayachkivska OS, Gzhegotsky MR, Terletska OI, Lutsyk DA, Yaschenko AM, Dzhura OR. Influence of Viburnum opulus proanthocyanidins on stress-induced gastrointestinal mucosal damage. J Physiol Pharmacol 2006;57(Suppl 5):155-67.

44. Brzozowski T, Konturek PC, Drozdowicz D, Konturek SJ, Zayachivska O, Pajdo R, et al. Grapefruit-seed extract attenuates ethanol-and stressinduced gastric lesions via activation of prostaglandin, nitric oxide and sensory nerve pathways. World J Gastroenterol 2005;11:6450-8.

45. Rodrigues PA, Morais SM, Souza CM, Magalhães DV, Vieira IG, Andrade GM, et al. Gastroprotective effect of Byrsonima sericea DC leaf extract against ethanol-induced gastric injury and its possible mechanisms of action. An Acad Bras Cienc 2012;84:113-22.

46. Prabha T, Dorababu M, Goel S, Agarwal PK, Singh A, Joshi VK, et al. Effect of methanolic extract of Pongamia pinnata Linn seed on gastroduodenal ulceration and mucosal offensive and defensive factors in rats. Indian J Exp Biol 2009;47:649-59.
47. Nielsen SE, Young JF, Daneshvar B, Lauridsen ST, Knuthsen P, Sandström $\mathrm{B}$, et al. Effect of parsley (Petroselinum crispum) intake on urinary apigenin excretion, blood antioxidant enzymes and biomarkers for oxidative stress in human subjects. Br J Nutr 1999;81:447-55.

48. Phillipson M, Johansson ME, Henriksnäs J, Petersson J, Gendler SJ, Sandler S, et al. The gastric mucus layers: constituents and regulation accumulation. Am J Physiol Gastrointest Liver Physiol 2008;295:806-12.

49. Baczek J, Laskowiec G. Lansoprazol ++: a new proton pump inhibitor. Pol Merkur Lekarski 1998;4:339-41.

50. Matsuzaki J, Suzuki H, Minegishi Y, Sugai E, Tsugawa H, Yasui M, et al. Acid suppression by proton pump inhibitors enhances aquaporin-4 and KCNQ1 expression ingastric fundic parietal cells in mouse. Dig Dis Sci 2010;55:3339-48.

51. Bandyopadhyay D, Bandyopadhyay A, Das PK, Reiter RJ. Melatonin protects against gastric ulceration and increases the efficacy of ranitidine and omeprazole in reducing gastric damage. J Pineal Res 2002;33:1-7.

52. Biswas K, Bandyopadhyay U, Chattopadhyay I, Varadaraj A, Ali E, Banerjee RK. A novel antioxidant and antiapoptotic role of omeprazole to block gastric ulcer through scavenging of hydroxyl radical. J Biol Chem 2003;278:10993-1001.

53. Nakamura M, Akiba Y, Kishikawa H, Oda M, Ishii H. Effect of combined administration of lansoprazole and sofalcone on microvascular and connective tissue regeneration after ethanol-induced gastric mucosal damage. J Clin Gastroenterol 1998;27(Suppl 1):170-7.

54. Maity P, Bindu S, Choubey V, Alam A, Mitra K, Goyal M, et al. Lansoprazole protects and heals gastric mucosa from non-steroidal anti-inflammatory drug (NSAID)-induced gastropathy by inhibiting mitochondrial as well as Fas mediated death pathways with concurrent induction of mucosal cell renewal. J Biol Chem 2008;283:14391-401.

55. Blandizzi C, Natale G, Gherardi G, Lazzeri G, Marveggio C, Colucci R. et al. Acid-independent gastroprotective effects of lansoprazole in experimental mucosal injury. Dig Dis Sci 1999;44:2039-50.

56. Nakamura M, Akiba Y, Oda M, Ishii H. Appearance of myofibroblasts in the gastric mucosa after ingestion of ethanol and lansoprazole with reevaluation of the mucoid cap. Alcohol Clin Exp Res 1998;22(3 Suppl):115-20.

57. Komuro Y, Ishii K, Miyake Y, Tanabe S, Oida M, Saigenji K. Effect of lansoprazole on gastric ulcer healing and mucin content. J Clin Gastroenterol 1995;20(Suppl 2):47-51.

58. Saegusa $Y$, Ichikawa T, Iwai T, Goso Y, Ikezawa T, Nakano M, et al. Effects of acid antisecretory drugs on mucus barrier of the rat against 5-fluorouracil-induced gastrointestinal mucositis. Scand J Gastroenterol 2008;43:531-7.

59. Agnihotri N, Kaur H, Kaur N, Sarotra P. Role of oxidative stress in lansoprazole-mediated gastric and hepatic protection in Wistar rats. Indian J Gastroenterol 2007;26;118-21.

60. Natale G, Lazzeri G, Lubrano V, Colucci R, Vassalle C, Fornai M., et al. Mechanisms of gastroprotection by lansoprazole pretreatment against experimentally induced injury in rats: role of mucosal oxidative damage and sulfhydryl compounds. Toxicol Appl Pharmacol 2004;195:62-72.

61. Shin JM, Sachs G. Restoration of acid secretion following treatment with proton pump inhibitors. Gastroenterology 2002;123:1588-97. 